\title{
Tensile properties of kenaf yarn fibre reinforced unsaturated polyester composites at different fibre orientations
}

\begin{abstract}
This paper reported the study of tensile properties of kenaf yarn fibre reinforced unsaturated polyester (UP) composites at different fibre orientations, i.e. $00, \pm 45 \mathrm{o}$ and $90 \mathrm{o}$. It is concluded that composites with 0o orientation show higher strength and stiffness than composites with $\pm 45 \mathrm{o}$ and $90 \mathrm{o}$ angle fibre orientation. The highest value of stress is $29 \mathrm{MPa}$ for $0^{\circ}$ loading direction followed by $\pm 45^{\circ}$ loading direction $\left(28 \mathrm{MPa}\right.$ ) and $90^{\circ}$ loading direction has the lowest stress value of $6 \mathrm{MPa}$. Tensile modulus results revealed the highest value of $10.61 \mathrm{GPa}$ for $0^{\circ}$ loading direction and the tensile modulus for $45^{\circ}$ orientation of loading direction is $5 \mathrm{GPa}$, followed by the modulus for $90^{\circ}$ of fibre loading direction of 1.2 $\mathrm{GPa}$; which is the lowest. Results showed that the highest temperature was concentrated at tool edge for Ti6Al4V.
\end{abstract}

Keyword: Fibre orientation; Kenaf yarn fibre; Tensile properties; Unsaturated polyester 